\title{
Abiotic and biotic processes that drive carboxylation and decarboxylation reactions of
}

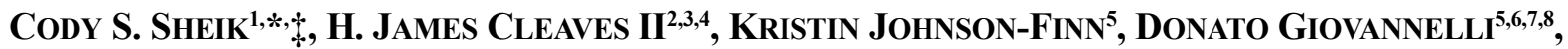

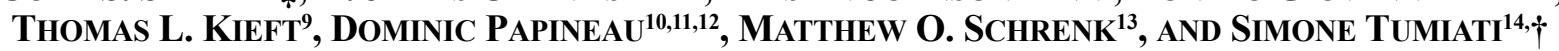

\author{
${ }^{1}$ Department of Biology and the Large Lakes Observatory, University of Minnesota Duluth, Duluth, Minnesota 55812, U.S.A. \\ ${ }^{2}$ Earth-Life Science Institute, Tokyo Institute of Technology, 2-12-1-IE-1 Ookayama Meguro-ku, Tokyo 152-8550, Japan \\ ${ }^{3}$ Institute for Advanced Study, 1 Einstein Drive, Princeton, New Jersey 08540, U.S.A. \\ ${ }^{4}$ Blue Marble Space Institute of Science, Seattle, Washington 98154, U.S.A. \\ ${ }^{5}$ Earth-Life Science Institute, Tokyo Institute of Technology, 2-12-1-IE-1 Ookayama Meguro-ku, Tokyo 152-8550, Japan \\ ${ }^{6}$ Department of Biology, University of Naples "Federico II", Monte Sant'Angelo, 80120 Naples, Italy \\ ${ }^{7}$ Department of Marine and Coastal Science, Rutgers University, 71 Dudley Road, New Brunswick, New Jersey 08901, U.S.A. \\ ${ }^{8}$ Institute for Marine Biological and Biotechnological Resources, National Research Council of Italy, CNR-IRBIM, Ancona, Italy \\ ${ }^{9}$ New Mexico Institute of Mining and Technology, Socorro, New Mexico 87801, U.S.A. \\ ${ }^{10}$ London Centre for Nanotechnology, 17-19 Gordon Street, University College London, London WC1H 0AH, U.K. \\ ${ }^{11}$ Department of Earth Sciences, University College London, London WC1E 6BT, U.K. \\ ${ }^{12}$ Centre for Planetary Sciences, University College London and Birkbeck University of London, London WC1E 6BT, U.K \\ ${ }^{13}$ Department of Earth and Environmental Sciences, Michigan State University, East Lansing, Michigan 48824, U.S.A. \\ ${ }^{14}$ Dipartimento di Scienze della Terra, University of Milan, via Mangiagalli 34, 20133 Milan, Italy
}

\begin{abstract}
Carboxylation and decarboxylation are two fundamental classes of reactions that impact the cycling of carbon in and on Earth's crust. These reactions play important roles in both long-term (primarily abiotic) and short-term (primarily biotic) carbon cycling. Long-term cycling is important in the subsurface and at subduction zones where organic carbon is decomposed and outgassed or recycled back to the mantle. Short-term reactions are driven by biology and have the ability to rapidly convert $\mathrm{CO}_{2}$ to biomass and vice versa. For instance, carboxylation is a critical reaction in primary production and metabolic pathways like photosynthesis in which sunlight provides energy to drive carbon fixation, whereas decarboxylation is a critical reaction in metabolic pathways like respiration and the tricarboxylic acid cycle. Early life and prebiotic chemistry on Earth likely relied heavily upon the abiotic synthesis of carboxylic acids. Over time, life has diversified (de)carboxylation reactions and incorporated them into many facets of cellular metabolism. Here we present a broad overview of the importance of carboxylation and decarboxylation reactions from both abiotic and biotic perspectives to highlight the importance of these reactions and compounds to planetary evolution.
\end{abstract}

Keywords: Decarboxylation, carboxylation, subduction recycling, biological carbon cycling, early Earth; Earth in Five Reactions: A Deep Carbon Perspective

\section{INTRODUCTION}

Earth's carbon cycle consists of a complex interplay of biological and abiological processes that together contribute to making Earth unique among the planets in our solar system. For life living on and in Earth's crust, carbon is a primary element and represents approximately $48 \%$ of the dry weight biomass of almost all organisms. Life's tight coupling to the carbon cycle is an important feature of our planet, and organisms have evolved many complex mechanisms for scavenging and transforming carbon in the environment. The contemporary carbon cycle stands in stark contrast to how the carbon cycle likely operated over much of Earth's history. Prior to the emergence of microbial life sometime before $3.5 \mathrm{Ga}$, the abiological carbon cycle consisted of simple organic molecules, including amino acids (Miller 1953).

\footnotetext{
* E-mail: cssheik@d.umn.edu. Orcid 0000-0003-0413-1924.

$\uparrow$ Orcid 0000-0003-0900-6145.

† Special collection papers can be found online at http://www.minsocam.org/MSA/ AmMin/special-collections.html.

of Open access: Article available to all readers online. This article is CC-BY-NC-ND.
}

However, as life on Earth began to diversify and the redox states of Earth's oceans and atmospheres began to change, the carbon cycle diversified in tandem.

\section{SOURCES AND TRANSFORMATION OF CARBON ON EARTH}

As Earth's carbon cycle evolved, several core biological and abiological reactions were key, and these were heavily affected by the prevailing oxidation state of carbon. Due to carbon's intrinsic properties (e.g., bond lengths and strengths in combination with other elements, large number of oxidation states, tetravalency, etc.), there are estimated to be as many as $10^{80}$ possible constitutional isomers of $\mathrm{C}$ under 500 atomic mass units (amu) (Lipinski and Hopkins 2004). Few of these are likely to be actualized. Remarkably, terrestrial life relies on a relatively small proportion of these, tens to hundreds of primary metabolites (Dobson 2004; Smith and Morowitz 2004) and few hundred thousand secondary metabolites (Ji et al. 2009). Carbon compounds occupy various metastable oxidation states, ranging from +4 to -4 , for $\mathrm{CO}_{2}$ and $\mathrm{CH}_{4}$, respectively. 
At the heart of the modern carbon cycle is the reduction of $\mathrm{CO}_{2}$ (inorganic) to form reduced organic compounds and the stepwise oxidation of organic $\mathrm{C}$ back to $\mathrm{CO}_{2}$ (Fig. 1). Many of these reactions can be generalized as carboxylations, i.e., the addition of $\mathrm{CO}_{2}$ to an existing organic molecule, yielding carboxylic acids, and decarboxylations, the loss of carboxylic acid groups and their release as $\mathrm{CO}_{2}$. Carboxylations and decarboxylations can occur either biotically through enzymatic mechanisms or abiotically, for example, via the influence of UV light (Getoff 1965; Chiu et al. 2017), thermal chemistry (see Papineau et al. 2017 and below), or the influence of mineral interactions (Weber 2004).

Carboxylation reactions can be generalized into long-term (or slow; $>100000$ years) processes and short-term (or fast; decades or less) C cycle processes (Berner 2003). With the advent and diversification of life, the rate of short-term, biological $\mathrm{C}$ cycling has increased relative to the rate of long-term, primarily abiotic processes. Short-term biological cycling operates at rates many orders of magnitude faster than long-term cycling. Throughout Earth's history, the balance between these carboxylation and decarboxylation reactions has influenced Earth's climate (Archer 2008; Lacis et al. 2010).

\section{LONG-TERM CARBON CYCLE}

The long-term cycle is primarily abiotic and likely has occurred over most of Earth's history (Rothman et al. 2003), and it depends upon plate tectonics, as the subducting plates bring both organic and inorganic carbon fixed at the surface into the solid Earth. The subducted carbon has at least two major fates, it can be emitted as volatiles through volcanism, or it can be returned to the mantle where it can be converted to various forms. The phases of carbon in the mantle (fluid, solid, or dissolved) depend on the pressure, intensity, and rate of heating, as well as the ambient redox conditions, but graphite, carbon dioxide, and methane are likely abundant species (Fig. 2). Ultimately, the quantity and ratio of reduced to oxidized carbon and its proxies in the subducting material are influenced by the redox state of both the deep Earth and atmosphere (Hayes and Waldbauer 2006).

\section{SHORT-TERM CARBON CYCLE}

The short-term cycle is essentially biotic and therefore unique to Earth, at least as far as current knowledge extends. Biological $\mathrm{C}$ cycling is a balance between (1) autotrophic $\mathrm{CO}_{2}$ fixation (carboxylation), which occurs primarily through the Calvin-BensonBassham Cycle (CBB) used by diverse groups of bacteria, archaea, and photosynthetic eukaryotes (Erb and Zarzycki 2018), and (2) the biological degradation of organic matter to $\mathrm{CO}_{2}$ through fermentation and respiration (decarboxylation). Biogenic and thermogenic methane serve as additional important shunts between biologically derived and non-biologically derived carbon pools, as methane may be converted first to $\mathrm{CO}_{2}$ then incorporated to biomass via the CBB cycle (Murrell and Jetten 2009; Chistoserdova 2011). Finally, fixed biological $\mathrm{C}$ is also oxidized via anthropogenic combustion of biomass and fossil fuels.

Micro-organisms were the major life forms on Earth in terms of biomass until relatively recently, having been dethroned by terrestrial plants in the last few hundred million years (Bar-On et al. 2018; McMahon and Parnell 2018). Interestingly, there are few primary biological $\mathrm{C}$ fixation pathways (Fuchs 2011) relative to the diversity of microbial life (Hug et al. 2016). Nonetheless, as life diversified and evolved, so too did cellular biochemistry resulting in the evolution of wholly new classes of organic compounds, such as lignin produced by vascular plants and some algae (Martone et al. 2009).

\section{ABIOTIC PROCESSES}

\section{Abiotic carboxylation reactions}

Fischer-Tropsch type (FTT) synthesis is a primary pathway for abiotic carboxylic acid formation. This class of reactions can plausibly occur under hydrothermal conditions via the reduction of $\mathrm{CO}_{2}, \mathrm{CO}$, or $\mathrm{HCO}_{3}^{-}$with $\mathrm{H}_{2}$ in the presence of transition metal catalysts (i.e., $\mathrm{Ni}, \mathrm{Cr}$, and $\mathrm{Fe}$ ), which produces short-chained alkanes and simple carboxylic acids, like formate, oxalate, and short fatty acids (Berndt et al. 1996; Foustoukos and Seyfried 2004). A large range of carboxylic acids have been experimentally synthesized in FTT reactions using formate as a reactant, which also easily forms under these hydrothermal conditions (McCollom and Simoneit 1999), though it should be pointed out the widespread occurrence of such abiotic synthesis on Earth has been recently called into question (Fiebig et al. 2019). Furthermore, phosphatized fatty

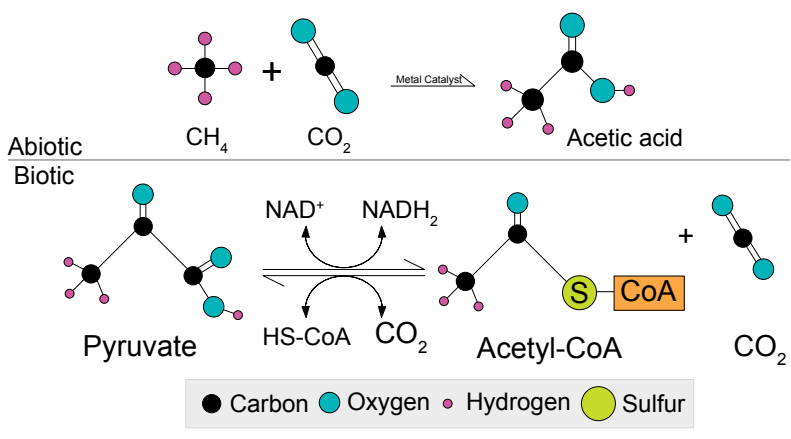

FIGURE 1. An example of an abiotic carboxylation (top) and a reversible biotic decarboxylation (left to right) and carboxylation (right to left) reaction. Abbreviations: $\mathrm{S}-\mathrm{CoA}=\mathrm{Co}$-enzyme $\mathrm{A}$, which is used to create thioesters of carboxylic acids, and $\mathrm{NAD}^{+} / \mathrm{NADH}_{2}=$ oxidized and reduced forms of Nicotinamide Adenine Dinucleotide, a commonly used electron donor/acceptor in cells.

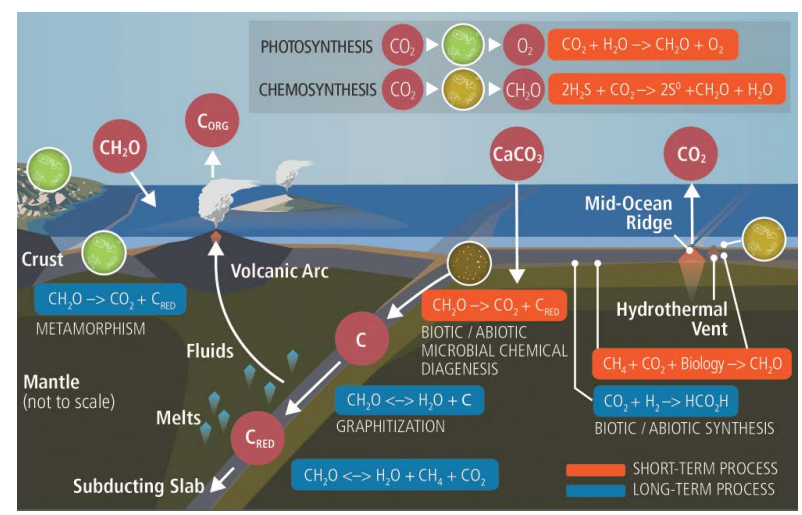

FIGURE 2. A simplified depiction of key carboxylation and decarboxylation reactions and their association with short- and long-term terrestrial carbon cycling. Long-term processes are depicted by blue boxes and short-term processes in orange. 
acids (also called phospholipids) can self-assemble into micelles in aqueous solutions (Chen and Walde 2010). As the complexity of cells evolved, fatty acids would evolve specific roles in cellular membranes, giving them unique properties, such as self-assembly into micelles (Segré et al. 2001). FTT synthesis has been used to explain the origin of carboxylic acids and various other hydrocarbons in hydrothermal vents (Rushdi and Simoneit 2006; McCollom and Seewald 2007), deep crustal settings (Sherwood Lollar et al. 2002), and meteorites (Sephton 2002; Steele et al. 2016).

\section{Decarboxylation reactions at high-pressures and temperatures}

As part of the long-term cycling of carbon, subduction zones play a direct role in returning surface carbon to the mantle (Kelemen and Manning 2015). Near-continent sediments can be very rich in organic matter (up to $60 \mathrm{wt} \%$, Mayer 1994), for instance, sediments formed during anoxic events or located in near-shore environments with highly productive overlying waters (Hartnett et al. 1998). Once these sediments are subducted, their organic carbon content can be transported down to the upper mantle, as suggested by the ${ }^{12} \mathrm{C}$-enriched isotopic signature of diamonds derived from the upper mantle, the transition zone and lower mantle (Stachel et al. 2002; Cartigny et al. 2004; Palot et al. 2016). Kelemen and Manning (2015) revised upward the maximum flux of carbon subducted in sediments from $17 \mathrm{Mt} \mathrm{C} / \mathrm{yr}$ to $23 \mathrm{Mt} \mathrm{C} / \mathrm{yr}$, adding the previously neglected contribution of organic carbon averaged to around $1 \mathrm{wt} \%$. However, the fate of organic matter in subduction zones is still debated, and present knowledge relies mostly on experimental studies focused on the interaction between crystalline graphite and aqueous fluids (Poli et al. 2009; Tumiati et al. 2013, 2017) or melts (Duncan and Dasgupta 2017).

Organic matter can have an impact on $\mathrm{CO}_{2}$ degassing in subduction zones, thus understanding pre-graphite states of organic matter may provide valuable insight subduction zone carbon decomposition. Organic acids have been used since the 1960s as sources of C-O-H fluids in high-pressure (HP)/high-temperature (HT) experiments (Supplemental ${ }^{1}$ Table S1), because they decompose at relatively low temperatures generating complex carbonbearing fluid mixtures depending on their bulk composition (i.e., the $\mathrm{C} / \mathrm{O} / \mathrm{H}$ ratios). For instance, oxalic acid dihydrate decomposes to $\mathrm{CO}_{2}$ at $150-200{ }^{\circ} \mathrm{C}$ (Pernert 1952; Morgan et al. 1992; Tiraboschi et al. 2016) through the reaction:

$$
\mathrm{C}_{2} \mathrm{H}_{2} \mathrm{O}_{4}+2 \mathrm{H}_{2} \mathrm{O} \rightarrow 2 \mathrm{CO}_{2}+\mathrm{H}_{2}
$$

Since the pioneering work of Eugster and Skippen (1967), it is known that a range of $\mathrm{C}-\mathrm{O}-\mathrm{H}$ fluids can be generated in highpressure (HP)/high-temperature (HT) experiments, producing aqueous fluids containing both $\mathrm{CO}_{2}$ (i.e., oxidized $\mathrm{C}^{4+}$ carbon) and $\mathrm{CH}_{4}$ (i.e., reduced $\mathrm{C}^{4}$ carbon) depending on the starting organic compound (Fig. 3).

In principle, oxalic acid dihydrate (OAD) should decompose at $\mathrm{HP} / \mathrm{HT}$ conditions to producing produce graphite and a mixed $\mathrm{H}_{2} \mathrm{O}-\mathrm{CO}_{2}$ fluid, while anthracene (ATR) should evolve give nearly pure methane, glucose, and water (Fig. 3). In fact, the disproportionation reaction of oxalic acid and glucose to graphite + aqueous fluids bearing $\mathrm{CH}_{4}$ and $\mathrm{CO}_{2}$ has been observed experimentally (Yamaoka et al. 2002; McCubbin et al. 2014). However, in real-

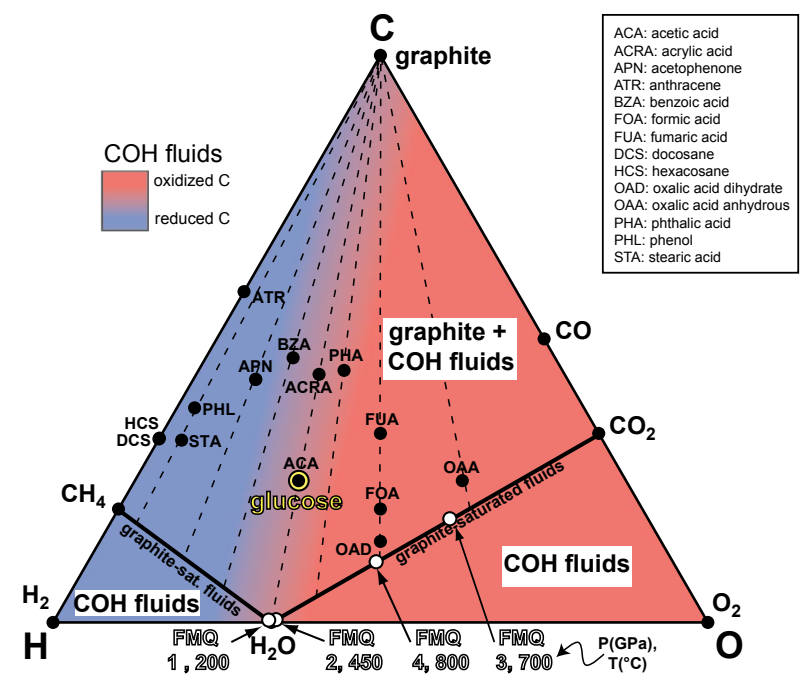

FIGURE 3. Ternary $\mathrm{COH}$ diagram showing a selection of organic compounds explored in high-pressure/high-temperature experiments. Glucose composition is emphasized in yellow. Solid black line: all possible compositions of $\mathrm{COH}$ fluids in equilibrium with pure crystalline graphite, calculated by thermodynamic modeling at $P-T$ conditions characterizing the subduction slab surface (Syracuse et al. 2010). Red and blue fields indicate, respectively, the presence of oxidized $\left(\mathrm{CO}_{2}\right)$ and of reduced $\left(\mathrm{CH}_{4}\right)$ volatile carbon species in $\mathrm{COH}$ fluids. Dashed lines join graphite with the expected composition of $\mathrm{COH}$ fluids in closed systems. White dots: calculated composition of $\mathrm{COH}$ fluids at different $P(\mathrm{GPa}), T\left({ }^{\circ} \mathrm{C}\right)$ in systems open to oxygen, where its fugacity is buffered externally at FMQ (fayalite/ferrosilite + magnetite + quartz/coesite) conditions. For every dot, $f_{\mathrm{O}_{2}}^{\mathrm{PMQ}}$ was first calculated using the Perple_X package (cf. Connolly 2005) and the thermodynamic database (2002 update) of Holland and Powell (1998). Then, the composition of the fluid has been calculated using the Perple_X routine "fluid" and the MRK equation of state of graphite-buffered C-O-H-S fluids (Eq. 7; Connolly and Cesare 1993), and it has been proven to be consistent with the $\mathrm{COH}$ fluid model of Zhang and Duan (2009). The dashed lines in the figure join graphite (or diamond, depending on pressure-temperature conditions) with the predicted composition of fluids in equilibrium with it (intercepts with the thick black line; Connolly and Cesare 1993; Zhang and Duan 2009), considering the decomposition of different organic compounds.

world fluid-rock systems, the redox state of the environment plays a major role (Tumiati and Malaspina 2019), such that the oxidation state of carbon in fluids in equilibrium with graphite depends on the oxygen fugacity conditions buffered by the rocks. Thus, $\mathrm{C}-\mathrm{O}-\mathrm{H}$ fluids will be $\mathrm{CO}_{2}$-bearing under oxidizing conditions and $\mathrm{CH}_{4}$ bearing $\left(\mathrm{C}^{0}+\mathrm{C}^{-4}\right)$ under reducing conditions, and is independent of the source organic compound's bulk composition.

Pressure and temperature are crucial to define defining whether a buffering mineral assemblage will impose oxidizing or reducing conditions. For instance, at oxygen fugacity conditions constrained by the equilibrium fayalite $+\mathrm{O}_{2}=$ magnetite + quartz (FMQ), often taken as a reference redox state for subducting slab-mantle interfaces (e.g., Tumiati and Malaspina 2019), C-O-H fluids in equilibrium with graphite should change their composition from nearly pure water containing traces of $\mathrm{CH}_{4}$ and $\mathrm{CO}_{2}$ at 1-2 GPa and $200-450{ }^{\circ} \mathrm{C}$, to mixed $\mathrm{H}_{2} \mathrm{O}-\mathrm{CO}_{2}$ fluids at $3-4 \mathrm{GPa}$ and $700-800{ }^{\circ} \mathrm{C}$ (Fig. 3). As a consequence, while graphite should be somewhat refractory to dissolution at forearc depths, it becomes readily soluble in aqueous fluids at subarc depths, which can dis- 
solve up to $80 \mathrm{~mol}_{\%} \mathrm{CO}_{2}$ in silicate-bearing systems (Tumiati et al. 2017). Moreover, although experimental data are not available yet, thermodynamic calculations suggest the dissolution of graphite in $\mathrm{HP}$ fluids may produce at certain $\mathrm{pH}-f_{\mathrm{O}_{2}}$ conditions carboxylic acids such as acetate, formate, propionate, and/or bicarbonate and carbonate (Sverjensky et al. 2014; Pan and Galli 2016; Tiraboschi et al. 2018). Nevertheless, as a general conclusion, we can infer that the fate of organic matter, represented below by $\mathrm{CH}_{2} \mathrm{O}$, is broadly governed in the deep Earth by the following reactions:

$$
\mathrm{CH}_{2} \mathrm{O} \rightarrow \mathrm{C}_{\text {(graphite) }}+\mathrm{H}_{2} \mathrm{O}
$$

which accounts for the graphitization of organic matter (Beyssac and Rumble 2014) and

$$
\begin{aligned}
& \mathrm{CH}_{2} \mathrm{O}+\mathrm{O}_{2} \rightarrow \mathrm{H}_{2} \mathrm{O}+\mathrm{CO}_{2} \\
& \mathrm{CH}_{2} \mathrm{O}+\mathrm{H}_{2} \mathrm{O} \rightarrow+\mathrm{CH}_{4}+\mathrm{O}_{2}
\end{aligned}
$$

which accounts for the oxidation (combustion) (Eq. 3) and for the reduction (abiotic methanation) (Eq. 4) of organic matter. At the high pressures and temperatures characterizing subduction zones, organic matter is therefore expected to be converted into carbon polymorphs (graphite, diamond) and aqueous fluids bearing carbon dissolved species that are constrained by the redox state and $\mathrm{pH}$ of the local environment.

\section{Roles of abiotic decarboxylation in subsurface carbon stores}

Decarboxylation reactions play important roles in the maturation of buried organic material on Earth. Carboxylic acid functional groups represent a significant portion of biological macromolecules (i.e., lipid membrane fatty acids, amino acids, and metabolic intermediates). Carboxylic acids thus constitute one of the main carbon reservoirs in living organisms and are heavily represented among the carbon species altered during diagenesis. In early stages of organic matter decomposition cell lysis releases free carboxylic acid-containing metabolites, which are readily taken up by other organisms. As decomposition progresses, membrane lipids undergo saponification, which liberates fatty acids. These free fatty acids often convert to anions or salts in sedimentary environments. As diagenesis progresses, carboxylic acids decompose abiotically via decarboxylation reactions to form alkanes and a mix of $\mathrm{CO}_{2}$, $\mathrm{CO}_{3}^{2-}$, and $\mathrm{HCO}_{3}^{-}$depending on factors such as $\mathrm{pH}$ and temperature. Decarboxylation reaction rates depend on $\mathrm{pH}$, temperature/depth, the concentration of reactants such as inorganic acids and oxidants, and the presence of catalysts (Weber 2004). The rate of decarboxylation influences on the formation of petroleum and its migration in the subsurface.

Thermocatalytic decarboxylation is a major abiotic pathway for the removal of carboxyl groups from organic molecules. Simple one carbon carboxylic acids, such as formic acid, decompose slowly in the absence of catalysts, but rates can be accelerated at higher temperatures $\left(>225^{\circ} \mathrm{C}\right)$ and controlled by equilibrium with $\mathrm{CO}_{2}$ (McCollom and Seewald 2003). As an example, acetic acid is thought to be formed in oil field brines, via decomposition of longchain carboxylic acids to form alkanes. Once the alkanes form, they are oxidized to alkenes, alcohols, and aldehydes to eventually form carboxylic acids. The resultant carboxylic acids can then decarboxylate to form $\mathrm{CO}_{2}$ and an $n-1$ alkane (Supplemental ${ }^{1}$ Fig. S1).

Likewise, the thermal decomposition of amino acids, which contain a carboxyl group as well as an amine group, is influenced by mineral assemblages, oxidation state, and dissolved species concentrations (Estrada et al. 2017). Some abiotic decarboxylation reactions may be oscillatory, a laboratory example of such a reaction is the Belousov-Zhabotinsky reaction, which produces $\mathrm{CO}_{2}$ from carboxylic acids with strong halogen oxidants, such as iodate and bromate, and strong acids like sulfuric and phosphonic acids (Zhabotinsky 1991; Papineau et al. 2017; Papineau 2020). During catagenesis and metagenesis, abiotic decarboxylation typically occurs in sedimentary layers below microbial habitability zones (e.g., of aerobic heterotrophy, sulfate reduction, fermentation, and methanogenesis), which can contribute to the production of porewater carbonate and the formation of concretionary structures (Irwin et al. 1977). Under higher temperature regimes, thermal cracking of alkanoic acids produces n-alkanes, which is a dominant pathway for the formation of petroleum (Kissin 1987). Production of heavy n-alkanes in kerogen occurs during the decarboxylation of fatty acids and esters and is slow under geological conditions (Kissin 1987; Weber 2004). Kerogen composition is described by its $\mathrm{O}$ and $\mathrm{H}$ composition, with kerogen type III having high $\mathrm{O} / \mathrm{C}$ and low $\mathrm{H} / \mathrm{C}$ atomic ratios, and kerogen type I having low $\mathrm{O} / \mathrm{C}$ and high $\mathrm{H} / \mathrm{C}$ atomic ratios; kerogen type II is intermediate between types I and III (Supplemental ${ }^{1}$ Fig. S2).

Coal is thought to be formed similarly by thermal decomposition: peat and lignite initially form during diagenesis and have the highest carboxylic acid content. Loss of $\mathrm{CO}_{2}$ from these source materials yields bituminous-grade coal, which contains progressively less volatiles (hydrocarbon gases) and carboxylic acids as it undergoes catagenesis. Eventually, nearly complete decarboxylation leads to the formation of anthracite coal through metagenesis and metamorphism (Supplemental ${ }^{1}$ Fig. S3).

\section{Biology's role in short-term carbon cycling}

Carboxylation and decarboxylation reactions are necessary for the building and deconstruction of cellular metabolites. As mentioned above, within the cell, carboxylic acid groups are prominent features of lipids, amino acids, and primary metabolites. Thus, carboxylic acids serve many structural roles as building blocks for cells. Additionally, carboxyl groups help maintain intracellular $\mathrm{pH}$ by acting as weak acids.

\section{BIOTIC CARBOXYLATION REACTIONS}

Biotic carboxylation reactions are crucial for photoautotrophic and chemoautotrophic life, and thus are necessary for biogeochemical cycling of all elements. Without carbon entering the system, cells would not be able to synthesize cellular material, including the enzymes that drive elemental cycling. Thus, carboxylation reactions are important not only for the cell itself, as they obviate the need for exogenous complex carbon compounds for growth, but they also likely drive micro and macro community assembly and dynamics.

Ecologically, primary producers, i.e., organisms that fix $\mathrm{CO}_{2}$, are keystone drivers of ecosystems, enabling biomass transfer to higher trophic levels. Thus, the carboxylation reactions they perform are essential for making carbon biologically active. Carbon fixation is an energy-consuming process for cells, and microbes have evolved several ways to fix carbon and offset the metabolic costs (Fuchs 2011). For example, phototrophs, like cyanobacte- 
ria or chloroplasts in plants, use the light energy to drive carbon fixation, while chemolithotrophs use energy stored in reduced chemical substrates (e.g., $\mathrm{H}_{2}, \mathrm{H}_{2} \mathrm{~S}, \mathrm{NH}_{3}$, or $\mathrm{Fe}^{2+}$ ). Here we will focus on a subset of these reactions.

One of the most widespread modes of carboxylation is the Calvin-Benson-Bassham cycle (CBB), using the enzyme ribulose-1,5bisphosphate carboxylase/oxygenase (RuBisCO). For both aquatic and terrestrial systems, this enzyme is commonly associated with photosynthesis as the RuBisCO and the CBB pathway accounts for the fixation of over $99.5 \%$ of all biological carbon on Earth (Raven 2009). In fact, RuBisCO is often considered to be the most abundant enzyme on Earth (Ellis 1979; Raven 2013). At the heart of the reaction, $\mathrm{RuBisCO}$ adds $\mathrm{CO}_{2}$ to a five-carbon sugar (ribulose-1,5-bisphosphate), creating an unstable six-carbon molecule that decomposes to give two 3-phosphoglycerate molecules (Fig. 4). Interestingly, despite being a leaky and energetically costly pathway, the CBB cycle operates in many energy-limited environments, e.g., subsurface environments (Lau et al. 2016), the deep ocean (Swan et al. 2011) as well as deep ocean and energy non-limited hydrothermal vents (Anantharaman et al. 2013; Sheik et al. 2014). The prominence of this enzyme and fixation cycle has altered the surface of Earth and its carbon isotopic signature over geological time scales.

The reverse Tricarboxylic Acid Cycle (rTCA), also known as the Arnon-Buchanan cycle, is considered the modern version of a proposed prebiotic autocatalytic cycle fueled by the formation of the highly insoluble mineral pyrite in sulfur-rich hydrothermal environments (Wächtershäuser 1988, 1990). Discovered in the anaerobic green phototrophic sulfur bacterium Chlorobium limicola, the pathway is a reversal of the citric acid cycle (the Krebs or TCA cycle), generating acetyl-CoA from two $\mathrm{CO}_{2}$ molecules. Widespread among anaerobic and microaerophilic bacteria, including all Aquificae, chemolithoautotrophic Epsilonproteobacteria, Chlorobi, and Nitrospirae (Berg 2011; Fuchs 2011; Hügler and Sievert 2011) in addition to few other bacterial strains, the rTCA cycle is energetically more favorable than the CBB cycle and appears to be widespread in subsurface and extreme environments. The dependence of two out of three carboxylation reactions on reduced ferredoxin has relegated this pathway to anaerobic/microaerophilic conditions due to the difficulty of keeping ferredoxin reduced in the presence of oxygen (Fuchs 2011). Two main variants of the cycle exist, symmetric and asymmetric, although the evolutionary reasons for their differentiation are not well understood (Aoshima et al. 2004; Braakman and Smith 2012; Giovannelli et al. 2017). In the asymmetric version of this pathway, isocitrate is formed directly via the NADPH-dependent carboxylation of 2-oxoglutarate. Interestingly, recent work has shown that several carboxyl intermediates of the rTCA cycle can be mediated by simple metal ions (Muchowska et al. 2017), suggesting a possible very early evolution of carbon fixation metabolism.

The Wood-Ljungdahl (WL) pathway is thought to be one of the most ancient microbial metabolisms for carbon fixation (Weiss et al. 2016). At its core are two carbon reduction reactions that form one carbon carboxyl intermediates that are then converted to the acetate (Fig. 4), hence this pathway is commonly referred to as acetogenesis. Some extant microorganisms, like sulfatereducing Deltaproteobacteria, are able to use the WL pathway for carbon fixation or for carbon mineralization by reversing the pathway (Ragsdale 2008). The WL pathway only operates in strict anaerobes, i.e., microbes that grow only under reducing conditions. Since anaerobic conditions were almost certainly dominant throughout Earth's history and most subsurface environments are reducing, the WL pathway is generally considered more ancient than the CBB pathway. This pathway may also be important in subsurface environments, due to its energetic efficiency (Cotton et al. 2018). Additionally, the reversibility of the WL pathway facilitates carbon mineralization, making this an interesting and multifaceted pathway (Ragsdale 2008).

\section{Biotic decarboxylation reactions}

Biological decarboxylation is essential for the recycling of fixed carbon and for creating new metabolic intermediates. Both autotrophic and heterotrophic organisms use decarboxylation reactions to interconvert metabolites among biosynthetic pathways. For many heterotrophic organisms, respiration fed by the Tricarboxylic Acid Cycle (TCA, also known as the Krebs cycle) is a central metabolic pathway that distributes metabolites among various biosynthetic pathways and enables the remineralization organic carbon (Fig. 4). Carbon enters this pathway via acetyl-CoA, is converted into various carboxylic acid intermediates, and finally released as $\mathrm{CO}_{2}$. The TCA cycle is capable of complete carbon mineralization, ultimately converting organic carbon to $\mathrm{CO}_{2}$, thus this pathway also generates electrons that are directed to electron acceptors like oxygen, nitrate, iron, and sulfate or methane. Alternatively, decarboxylation can occur through various fermentative pathways. Fermentation produces both $\mathrm{CO}_{2}$ and a reduced carbon compound, some of which are carboxylic acids, that can be further utilized by other organisms for growth. For instance, the breakdown and fermentation of organic matter to short-chain carboxylic acids by microorganisms in the gut is vital for human metabolism. At the ecosystem scale, the interplay between heterotrophy and autotrophy shapes and drives the short-term carbon cycle.

\section{Earth's evolving biotic carbon cycle}

As biological metabolism diversified over geologic time, it is likely that carbon and carboxyl compound diversity also in-

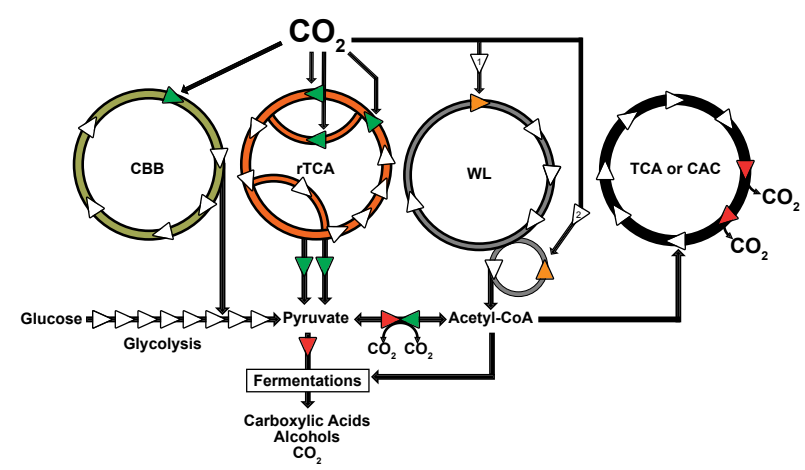

FIGURE 4. Examples of central carbon metabolisms microorganisms use to fix $\mathrm{CO}_{2}$ to biomass $(\mathrm{CBB}=$ Calvin-Benson-Bassham and $\mathrm{rTCA}=$ reverse Tricarboxylic Acid). Carbon mineralization to $\mathrm{CO}_{2}$ commonly occurs through fermentations or through the Tricarboxylic Acid (TCA) cycle. Green arrows represent carboxylation reactions, the red arrows represent decarboxylation steps, and orange arrows represent reductive carboxylations. 
creased. In extant organisms, carboxylation and decarboxylation reactions are ubiquitous and key for producing many metabolic intermediates and secondary metabolites. Several prominent, punctuated evolutionary developments have likely helped spur carbon diversity by providing new habitats and niches for life to expand into, such as meteorite impacts, plate tectonics, and the biologically driven oxygenation of the oceans and atmosphere. It is likely short-term carbon cycling has changed considerably over geological time.

The proliferation of oxygenic photosynthetic microorganisms during the Palaeoproterozoic Great Oxidation Event (GOE, between about 2.5 and $2.0 \mathrm{Ga}$ ) also coincided with widespread fixation of $\mathrm{CO}_{2}$ into biomass through CBB-mediated carboxylation. With copious amounts of $\mathrm{O}_{2}$ in the environment, new forms of metabolism such as aerobic respiration and new forms of life, including multicellular organisms, emerged (Han and Runnegar 1992; El Albani et al. 2019). Higher plants have contributed significantly to organic $\mathrm{C}$ diversity through production of myriad plant secondary compounds, i.e., lignin and phenolic acids (Renault et al. 2017). Concommitantly, as life developed the means to make new carboxyl compounds emerged, new decarboxylation pathways also evolved to degrade organic matter back to $\mathrm{CO}_{2}$.

\section{IMPLICATIONS}

Carboxylation and decarboxylation are an important class of chemical reactions that have helped shape life on the surface of Earth for billions of years. These reactions are driven through biotic and abiotic processes at different locations in and on Earth's crust. Prebiotic carboxylic acid synthesis may have been critical for the origin and development of life, which has been using this class of reactions for energy generation and reproduction for billions of years. Where these processes occur in the environment (i.e., subduction zones, coal deposit, aerobic water column, tropical forests) dictates the rates of reaction and the diversity of carboxylic acids produced. Whether produced biotically or abiotically, these individual simple reactions are at the heart of the complex and elegant pathways that cycle carbon on Earth and potentially on extraterrestrial planets.

\section{ACKNOWLEDGMENTS}

The authors thank the participants of the Deep Carbon Observatory's Earth in Five Reactions workshop that were originally part of the brainstorming session that served, in part, to form the basis of this manuscript. Specifically, we acknowledge Dan Colman, Tony Hartshorn, Adrienne Hoarfrost, and Gunter Wegener for their early input. A special thanks and to Josh Wood for help conceptualizing and illustrating Figure 2. We are also appreciative of the Deep Carbon Observatory for providing support for the workshop.

\section{REFERENCES CITED}

Anantharaman, K., Breier, J.A., Sheik, C.S., and Dick, G.J. (2013) Evidence for hydrogen oxidation and metabolic plasticity in widespread deep-sea sulfur-oxidizing bacteria. Proceedings of the National Academy of Sciences, 110, 330-335.

Aoshima, M., Ishii, M., and Igarashi, Y. (2004) A novel enzyme, citryl-CoA synthetase, catalysing the first step of the citrate cleavage reaction in Hydrogenobacter thermophilus TK-6. Molecular Microbiology, 52, 751-761.

Archer, D. (2008) Checking the thermostat. Nature Geoscience, 1, 289.

Bar-On, Y.M., Phillips, R., and Milo, R. (2018) The biomass distribution on Earth. Proceedings of the National Academy of Sciences, 115, 6506.

Berg, I.A. (2011) Ecological aspects of the distribution of different autotrophic $\mathrm{CO}_{2}$ fixation pathways. Applied and Environmental Microbiology, 77, 1925.

Berndt, M.E., Allen, D.E., and Seyfried, W.E. Jr (1996) Reduction of $\mathrm{CO}_{2}$ during serpentinization of olivine at $300^{\circ} \mathrm{C}$ and 500 bar. Geology, 24, 351-354.

Berner, R.A. (2003) The long-term carbon cycle, fossil fuels and atmospheric composition. Nature, 426, 323-326.

Beyssac, O., and Rumble, D. (2014) Graphitic carbon: A ubiquitous, diverse, and useful geomaterial. Elements, 10, 415-420

Braakman, R., and Smith, E. (2012) The emergence and early evolution of biological carbon-fixation. PLOS Computational Biology, 8, e1002455.

Cartigny, P., Stachel, T., Harris, J.W., and Javoy, M. (2004) Constraining diamond metasomatic growth using $\mathrm{C}$ - and $\mathrm{N}$-stable isotopes: examples from Namibia. Selected Papers from the Eighth International Kimberlite Conference. Volume 2: The J. Barry Hawthorne Volume, 77, 359-373.

Chen, I.A., and Walde, P. (2010) From self-assembled vesicles to protocells. Cold Spring Harbor Perspectives in Biology, 2.

Chistoserdova, L. (2011) Modularity of methylotrophy, revisited. Environmental Microbiology, 13, 2603-2622.

Chiu, R., Tinel, L., Gonzalez, L., Ciuraru, R., Bernard, F., George, C., and Volkamer, R. (2017) UV photochemistry of carboxylic acids at the air-sea boundary: A relevant source of glyoxal and other oxygenated VOC in the marine atmosphere. Geophysical Research Letters, 44, 1079-1087.

Connolly, J.A.D. (2005) Computation of phase equilibria by linear programming: A tool for geodynamic modeling and its application to subduction zone decarbonation. Earth and Planetary Science Letters, 236, 524-541.

Connolly, J.A., and Cesare, B. (1993) C-O-H-S fluid composition and oxygen fugacity in graphitic metapelites. Journal of Metamorphic Geology, 11, 379-388.

Cotton, C.A., Edlich-Muth, C., and Bar-Even, A. (2018) Reinforcing carbon fixation: $\mathrm{CO}_{2}$ reduction replacing and supporting carboxylation. Current Opinion in Biotechnology, 49, 49-56.

Dobson, C.M. (2004) Chemical space and biology. Nature, 432, 824-828.

Duncan, M.S., and Dasgupta, R. (2017) Rise of Earth's atmospheric oxygen controlled by efficient subduction of organic carbon. Nature Geoscience, 10, 387.

El Albani, A., Mangano, M.G., Buatois, L.A., Bengtson, S., Riboulleau, A., Bekker, A., Konhauser, K., Lyons, T., Rollion-Bard, C., Bankole, O., and others. (2019) Organism motility in an oxygenated shallow-marine environment 2.1 billion years ago. Proceedings of the National Academy of Sciences, 116, 3431.

Ellis, R.J. (1979) The most abundant protein in the world. Trends in Biochemical Sciences, 4, 241-244.

Erb, T.J., and Zarzycki, J. (2018) A short history of RubisCO: the rise and fall (?) of Nature's predominant $\mathrm{CO}_{2}$ fixing enzyme. Current Opinion in Biotechnology, 49, $100-107$.

Estrada, C.F., Mamajanov, I., Hao, J., Sverjensky, D.A., Cody, G.D., and Hazen, R.M. (2017) Aspartate transformation at $200^{\circ} \mathrm{C}$ with brucite $\left[\mathrm{Mg}(\mathrm{OH})_{2}\right], \mathrm{NH}_{3}$, and $\mathrm{H}_{2}$ : Implications for prebiotic molecules in hydrothermal systems. Chemical Geology, $457,162-172$

Eugster, H.P., and Skippen, G.B. (1967) Igneous and metamorphic reactions involving gas equilibria. In P.H. Abelson, Ed., Researches in Geochemistry, 2, pp. 492-520. Wiley.

Foustoukos, D.I., and Seyfried, W.E. (2004) Hydrocarbons in hydrothermal vent fluids: The role of chromium-bearing catalysts. Science, 304, 1002.

Fiebig, J., Stefánsson, A., Ricci, A., Tassi, F., Viveiros, F., Silva, C., Lopez, T.M., Schreiber, C., Hofmann, S., and Mountain, B.W. (2019) Abiogenesis not required to explain the origin of volcanic-hydrothermal hydrocarbons. Geochemical Perspectives Letters, 11, 23-27.

Fuchs, G. (2011)Alternative pathways of carbon dioxide fixation: Insights into the early evolution of life? Annual Review of Microbiology, 65, 631-658.

Getoff, N. (1965) Carboxylation of formic acid in aqueous solutions under the influence of U.V.-light. Photochemistry and Photobiology, 4, 433-438.

Giovannelli, D., Sievert, S.M., Hügler, M., Markert, S., Becher, D., Schweder, T., and Vetriani, C. (2017) Insight into the evolution of microbial metabolism from the deep-branching bacterium, Thermovibrio ammonificans. (J. Bohlmann, Ed.) eLife, 6, e18990.

Han, T., and Runnegar, B. (1992) Megascopic eukaryotic algae from the 2.1-billionyear-old negaunee iron-formation, Michigan. Science, 257, 232.

Hartnett, H.E., Keil, R.G., Hedges, J.I., and Devol, A.H. (1998) Influence of oxygen exposure time on organic carbon preservation in continental margin sediments. Nature, 391, 572-575.

Hayes, J.M., and Waldbauer, J.R. (2006) The carbon cycle and associated redox processes through time. Philosophical transactions of the Royal Society of London, Series B, Biological Sciences, 361, 931-950.

Holland, T.J., and Powell, R. (1998) An internally consistent thermodynamic data set for phases of petrological interest. Journal of Metamorphic Geology, 16, 309-343.

Hug, L.A., Baker, B.J., Anantharaman, K., Brown, C.T., Probst, A.J., Castelle, C.J., Butterfield, C.N., Hernsdorf, A.W., Amano, Y., Ise, K., and others. (2016) A new view of the tree of life. Nature Microbiology, 1, 16048.

Hügler, M., and Sievert, S.M. (2011) Beyond the Calvin cycle: Autotrophic carbon fixation in the ocean. Annual Review of Marine Science, 3, 261-289.

Irwin, H., Curtis, C., and Coleman, M. (1977) Isotopic evidence for source of diagenetic carbonates formed during burial of organic-rich sediments. Nature, 269, 209-213.

Ji, H.-F., Li, X.-J., and Zhang, H.-Y. (2009) Natural products and drug discovery. Can thousands of years of ancient medical knowledge lead us to new and powerful drug combinations in the fight against cancer and dementia? EMBO reports, 10, 194-200.

Kelemen, P.B., and Manning, C.E. (2015) Reevaluating carbon fluxes in subduction zones, what goes down, mostly comes up. Proceedings of the National Academy of Sciences, DOI: 10.1073/pnas.1507889112.

Kissin, Y.V. (1987) Catagenesis and composition of petroleum: Origin of n-alkanes and 
isoalkanes in petroleum crudes. Geochimica et Cosmochimica Acta, 51, 2445-2457.

Lacis, A.A., Schmidt, G.A., Rind, D., and Ruedy, R.A. (2010) Atmospheric $\mathrm{CO}_{2}$ : Principal control knob governing Earth's temperature. Science, 330, 356.

Lau, M.C.Y., Kieft, T.L., Kuloyo, O., Linage-Alvarez, B., van Heerden, E., Lindsay, M.R., Magnabosco, C., Wang, W., Wiggins, J.B., Guo, L., and others. (2016) An oligotrophic deep-subsurface community dependent on syntrophy is dominated by sulfur-driven autotrophic denitrifiers. Proceedings of the National Academy of Sciences, 113, E7927.

Lipinski, C., and Hopkins, A. (2004) Navigating chemical space for biology and medicine. Nature, 432, 855-861.

Mall, A., Sobotta, J., Huber, C., Tschirner, C., Kowarschik, S., Bačnik, K., Mergelsberg, M., Boll, M., Hügler, M., Eisenreich, W., and others. (2018) Reversibility of citrate synthase allows autotrophic growth of a thermophilic bacterium. Science, 359, 563.

Martone, P.T., Estevez, J.M., Lu, F., Ruel, K., Denny, M.W., Somerville, C., and Ralph, J. (2009) Discovery of lignin in seaweed reveals convergent evolution of cell-wall architecture. Current Biology, 19, 169-175.

Mayer, L.M. (1994) Surface area control of organic carbon accumulation in continental shelf sediments. Geochimica et Cosmochimica Acta, 58, 1271-1284.

McCollom, T.M., and Seewald, J.S. (2003) Experimental constraints on the hydrothermal reactivity of organic acids and acid anions: I. Formic acid and formate. Geochimica et Cosmochimica Acta, 67, 3625-3644.

- (2007) Abiotic synthesis of organic compounds in deep-sea hydrothermal environments. Chemical Reviews, 107, 382-401.

McCollom, T.M., and Simoneit, B.R.T. (1999) Abiotic formation of hydrocarbons and oxygenated compounds during thermal decomposition of iron oxalate. Origins of Life and Evolution of the Biosphere, 29, 167-186.

McCubbin, F.M., Sverjensky, D.A., Steele, A., and Mysen, B.O. (2014) In-situ characterization of oxalic acid breakdown at elevated $P$ and $T$ : Implications for organic C-O-H fluid sources in petrologic experiments. American Mineralogist, 99, 2258.

McMahon, S., and Parnell, J. (2018) The deep history of Earth's biomass. Journal of the Geological Society, 175, 716.

Miller, S.L. (1953) A production of amino acids under possible primitive earth conditions. Science, 117, 528.

Morgan, G.B., Chou, I.-M., and Pasteris, J.D. (1992) Speciation in experimental C-O-H fluids produced by the thermal dissociation of oxalic acid dihydrate. Geochimica et Cosmochimica Acta, 56, 281-294.

Muchowska, K.B., Varma, S.J., Chevallot-Beroux, E., Lethuillier-Karl, L., Li, G., and Moran, J. (2017) Metals promote sequences of the reverse Krebs cycle. Nature Ecology \& Evolution, 1, 1716-1721.

Murrell, J.C., and Jetten, M.S.M. (2009) The microbial methane cycle. Environmental Microbiology Reports, 1, 279-284.

Palot, M., Jacobsen, S.D., Townsend, J.P., Nestola, F., Marquardt, K., Miyajima, N., Harris, J.W., Stachel, T., McCammon, C.A., and Pearson, D.G. (2016) Evidence for $\mathrm{H}_{2} \mathrm{O}$-bearing fluids in the lower mantle from diamond inclusion. The Nature of Diamonds and Their Use in Earth's Study, 265, 237-243.

Pan, D., and Galli, G. (2016) The fate of carbon dioxide in water-rich fluids under extreme conditions. Science Advances, 2, e1601278.

Papineau, D. (2020) Chemically oscillating reactions in the formation of botryoidal malachite. American Mineralogist, 105, https://doi.org/10.2138/am-2020-7029

Papineau, D., She, Z., and Dodd, M.S. (2017) Chemically-oscillating reactions during the diagenetic oxidation of organic matter and in the formation of granules in late Palaeoproterozoic chert from Lake Superior. Chemical Geology, 470, 33-54.

Pernert, J.C. (1952) Oxalic acid. In R.E. Kirk and D.F. Othmer, Eds., Encylopedia of Chemical Technology, 9, pp. 661-674. Interscience.

Poli, S., Franzolin, E., Fumagalli, P., and Crottini, A. (2009) The transport of carbon and hydrogen in subducted oceanic crust: An experimental study to $5 \mathrm{GPa}$. Earth and Planetary Science Letters, 278, 350-360.

Ragsdale, S.W. (2008) Enzymology of the Wood-Ljungdahl pathway of acetogenesis. Annals of the New York Academy of Sciences, 1125, 129-136.

Raven, J.A. (2009) Contributions of anoxygenic and oxygenic phototrophy and chemolithotrophy to carbon and oxygen fluxes in aquatic environments. Aquatic Microbial Ecology, 56, 177-192.

(2013) Rubisco: still the most abundant protein of Earth? New Phytologist, 198, 1-3.

Renault, H., Alber, A., Horst, N.A., Basilio Lopes, A., Fich, E.A., Kriegshauser, L., Wiedemann, G., Ullmann, P., Herrgott, L., Erhardt, M., and others. (2017) A phenol-enriched cuticle is ancestral to lignin evolution in land plants. Nature Communications, 8,14713

Rothman, D.H., Hayes, J.M., and Summons, R.E. (2003) Dynamics of the Neoproterozoic carbon cycle. Proceedings of the National Academy of Sciences, 100, 8124.

Rushdi, A.I., and Simoneit, B.R.T. (2006) Abiotic condensation synthesis of glyceride lipids and wax esters under simulated hydrothermal conditions. Origins of Life and Evolution of Biospheres, 36, 93-108.

Seewald, J.S. (2003) Organic-inorganic interactions in petroleum-producing sedimentary basins. Nature, 426, 327-333

Segré, D., Ben-Eli, D., Deamer, D.W., and Lancet, D. (2001) The Lipid World. Origins of Life and Evolution of the Biosphere, 31, 119-145.

Sephton, M.A. (2002) Organic compounds in carbonaceous meteorites. Natural Product Reports, 19, 292-311.

Sheik, C.S., Jain, S., and Dick, G.J. (2014) Metabolic flexibility of enigmatic SAR324 revealed through metagenomics and metatranscriptomics. Environmental Microbiology, 16, 304-317.

Sherwood Lollar, B., Westgate, T.D., Ward, J.A., Slater, G.F., and Lacrampe-Couloume, G. (2002) Abiogenic formation of alkanes in the Earth's crust as a minor source for global hydrocarbon reservoirs. Nature, 416, 522-524.

Smith, E., and Morowitz, H.J. (2004) Universality in intermediary metabolism. Proceedings of the National Academy of Sciences, 101, 13168.

Stachel, T., Harris, J., Aulbach, S., and Deines, P. (2002) Kankan diamonds (Guinea) III: $\delta^{13} \mathrm{C}$ and nitrogen characteristics of deep diamonds. Contributions to Mineralogy and Petrology, 142, 465-475.

Steele, A., McCubbin, F.M., and Fries, M.D. (2016) The provenance, formation, and implications of reduced carbon phases in Martian meteorites. Meteoritics \& Planetary Science, 51, 2203-2225.

Sverjensky, D.A., Stagno, V., and Huang, F. (2014) Important role for organic carbon in subduction-zone fluids in the deep carbon cycle. Nature Geoscience, 7, 909.

Swan, B.K., Martinez-Garcia, M., Preston, C.M., Sczyrba, A., Woyke, T., Lamy, D. Reinthaler, T., Poulton, N.J., Masland, E.D.P., Gomez, M.L., and others. (2011) Potential for chemolithoautotrophy among ubiquitous bacteria lineages in the dark ocean. Science, 333, 1296-1300.

Syracuse, E.M., van Keken, P.E., and Abers, G.A. (2010) The global range of subduction zone thermal models. Special Issue on Deep Slab and Mantle Dynamics, 183, 73-90.

Tiraboschi, C., Tumiati, S., Recchia, S., Miozzi, F., and Poli, S. (2016) Quantitative analysis of $\mathrm{COH}$ fluids synthesized at HP-HT conditions: an optimized methodology to measure volatiles in experimental capsules. Geofluids, 16, 841-855.

Tiraboschi, C., Tumiati, S., Sverjensky, D., Pettke, T., Ulmer, P., and Poli, S. (2018) Experimental determination of magnesia and silica solubilities in graphite-saturated and redox-buffered high-pressure $\mathrm{COH}$ fluids in equilibrium with forsterite + enstatite and magnesite + enstatite. Contributions to Mineralogy and Petrology, 173, 2.

Tumiati, S., and Malaspina, N. (2019) Redox processes and the role of carbon-bearing volatiles from the slab-mantle interface to the mantle wedge. Journal of the Geological Society, jgs2018-046.

Tumiati, S., Fumagalli, P., Tiraboschi, C., and Poli, S. (2013) An experimental study on $\mathrm{COH}$-bearing peridotite up to $3 \times 2 \mathrm{GPa}$ and implications for crust-mantle recycling. Journal of Petrology, 54, 453-479.

Tumiati, S., Tiraboschi, C., Sverjensky, D.A., Pettke, T., Recchia, S., Ulmer, P., Miozzi, F., and Poli, S. (2017) Silicate dissolution boosts the $\mathrm{CO}_{2}$ concentrations in subduction fluids. Nature Communications, $8,616$.

Wächtershäuser, G. (1988) Before enzymes and templates: theory of surface metabolism. Microbiological Reviews, 52, 452.

- (1990) Evolution of the first metabolic cycles. Proceedings of the National Academy of Sciences, 87, 200.

Weber, A.L. (2004) Kinetics of organic transformations under mild aqueous conditions: Implications for the origin of life and its metabolism. Origins of Life and Evolution of the Biosphere, 34, 473-495.

Weiss, M.C., Sousa, F.L., Mrnjavac, N., Neukirchen, S., Roettger, M., Nelson-Sathi, S., and Martin, W.F. (2016) The physiology and habitat of the last universal common ancestor. Nature Microbiology, 1, 16116.

Yamaoka, S., Shaji Kumar, M.D., Kanda, H., and Akaishi, M. (2002) Thermal decomposition of glucose and diamond formation under diamond-stable high pressure-high temperature conditions. Diamond and Related Materials, 11, 118-124.

Zhabotinsky, A.M. (1991) A history of chemical oscillations and waves. Chaos: An Interdisciplinary Journal of Nonlinear Science, 1, 379-386.

Zhang, C., and Duan, Z. (2009) A model for C-O-H fluid in the Earth's mantle. Geochimica et Cosmochimica Acta, 73, 2089-2102.

MANUSCRIPT RECEIVED JUNE 19, 2019

MANUSCRIPT ACCEPTED DECEMBER 21, 2019

MANUSCRIPT HANDLED BY JIE LI

\section{Endnote:}

${ }^{1}$ Deposit item AM-20-57166, Supplemental Material. Deposit items are free to all readers and found on the MSA website, via the specific issue's Table of Contents (go to http:// www.minsocam.org/MSA/AmMin/TOC/2020/May2020_data/May2020_data.html). 